\title{
"A Case Series on Low Testosterone Levels And Erectile Dysfunction In Male Diabetic Patients in Western U.P”
}

\author{
Dr. P.K Gupta ${ }^{1}$,Dr. Bharat Veer Manchanda ${ }^{2}$,Dr. Saurabh Sharma ${ }^{3}$, \\ Dr. Girish Dubey ${ }^{4}$,Dr. Sachin Gupta ${ }^{5}$, Dr.Akshit Mittal ${ }^{6}$ \\ ${ }^{1}$ Asso. Professor In Dept Of Medicine, Subharti Medical College, Meerut \\ ${ }^{2}$ Assi. Professor In Dept Of Medicine, Subharti Medical College, Meerut \\ ${ }^{3,4,5,6}$ Post Graduate In Dept Of Medicine, Subharti Medical College, Meerut
}

\section{Introduction}

Diabetes mellitus (DM) affects an estimated 285 million people worldwide. This number is expected to reach 438 million by the year 2030, with two-thirds of all cases occurring in low- to middle-income countries. Asians develop diabetes at a younger age, at lower degrees of obesity, and at much higher rates given the same amount of weight gain compared with Western populations. The association between low serum testosterone (LST) and DM has recently received substantial attention. Studies have reported that men with type 2 DM (T2DM) have a high prevalence of LST. Further, reduced total testosterone (TT) levels have been associated with insulin resistance and subsequent risk for developing T2DM. The main symptoms of LST are reduced libido/erectile dysfunction, reduced muscle mass and strength, increased adiposity, osteoporosis/low bone mass, depressed mood, fatigue, low energy, and impaired quality of life.

Researchers have highlighted the potential metabolic consequences of testosterone decline on ageassociated metabolic changes such as abdominal obesity, diabetes, and markers of prediabetes. Hypogonadism (HG) is a clinical condition consisting of both symptoms and biochemical signs of testosterone deficiency. However, many studies in men with diabetes have defined LST solely on the basis of testosterone levels. Symptoms of HG have rarely been considered in combination with biochemical testosterone deficiency. There is a growing interest in understanding the concurrence of symptoms of low testosterone and a low testosterone level since the clinical significance of a low testosterone level alone is unclear. TT concentrations are determined, to a large extent, by the circulating sex hormone binding globulin (SHBG) concentrations. In the blood of normal men, $44 \%$ of TT is bound to SHBG, $2 \%$ is unbound (free testosterone (FT)), and 54\% circulates bound to albumin and other proteins. This study was conducted to determine the prevalence of LST in men with $\mathrm{T} 2 \mathrm{DM}$ and its associated factors.

\section{Material And Method}

An observational study was performed in 50 patients(males) diabetic over the age of 50 years coming to medicine opd of CSSH, SUBHARTI MEDICAL COLLEGE, MEERUT. These patients were evaluated for diabetes control and complication, the presence of erectile dysfunction and for hypogonadism symptoms.

Morning serum testosterone levels were done.

Inclusion Criteria:-

All male diabetic patients older than 50 years were invited to participate in study.

\section{Exclusion Criteria:-}

Men on hormonal theraphy.

Men who had a surgical or chemical castration(for prostate cancer)

\section{Results}

Levels Of Testosterone

\begin{tabular}{|l|l|l|}
\hline Number of patients & Testosterone level & Percentage \\
\hline 28 & NORMAL & $56 \%$ \\
\hline 22 & LOW & $44 \%$ \\
\hline
\end{tabular}


“A Case Series On Low Testosterone Levels And Erectile Dysfunction In Male....

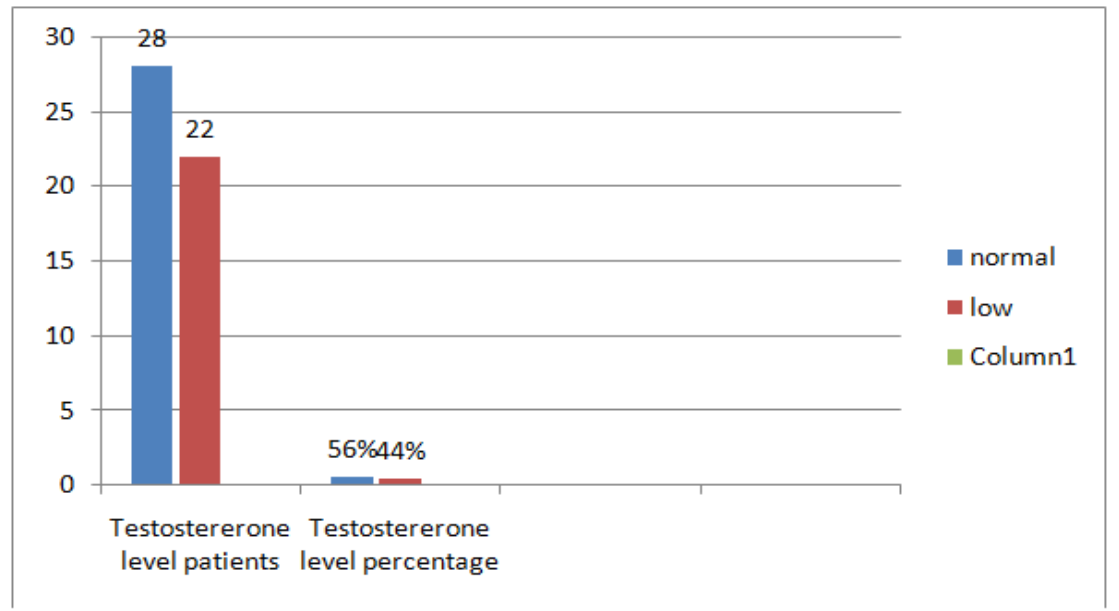

Erectile Dysfunction

\begin{tabular}{|l|l|l|}
\hline Number of patients & Erectile dysfunction & Percentage \\
\hline 23 & PRESENT & $46 \%$ \\
\hline 27 & ABSENT & $54 \%$ \\
\hline
\end{tabular}

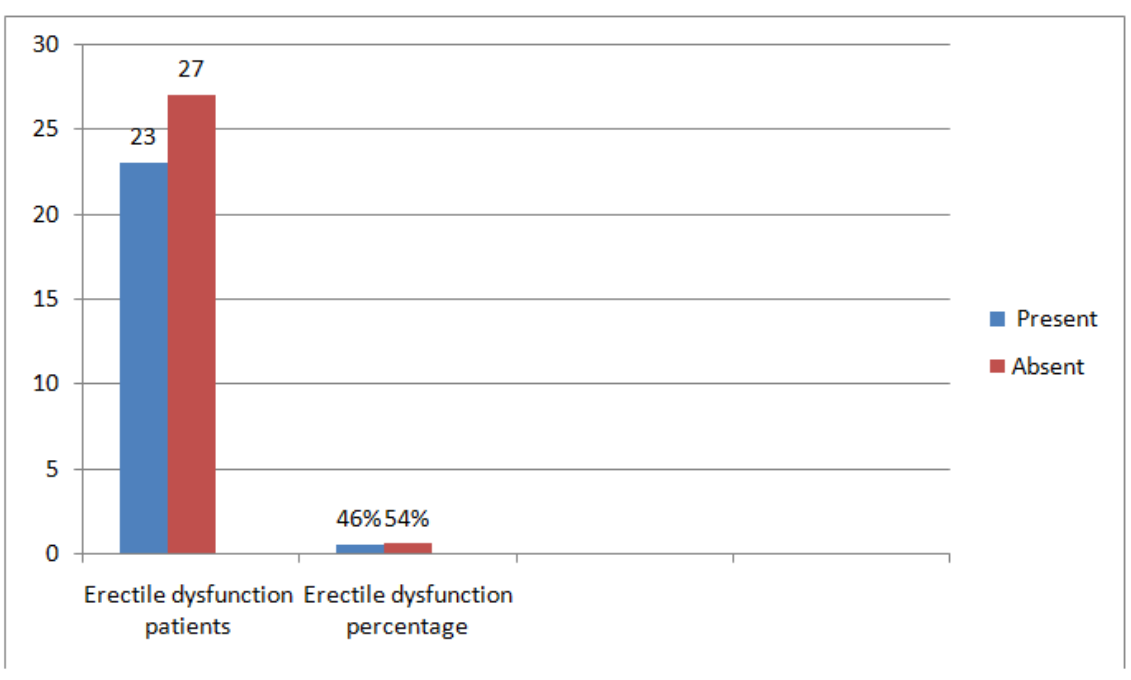

Features of metabolic syndrome

\begin{tabular}{|l|l|l|}
\hline Number of patients & Features & Percentage \\
\hline 38 & Present & $76 \%$ \\
\hline 12 & Absent & $24 \%$ \\
\hline
\end{tabular}

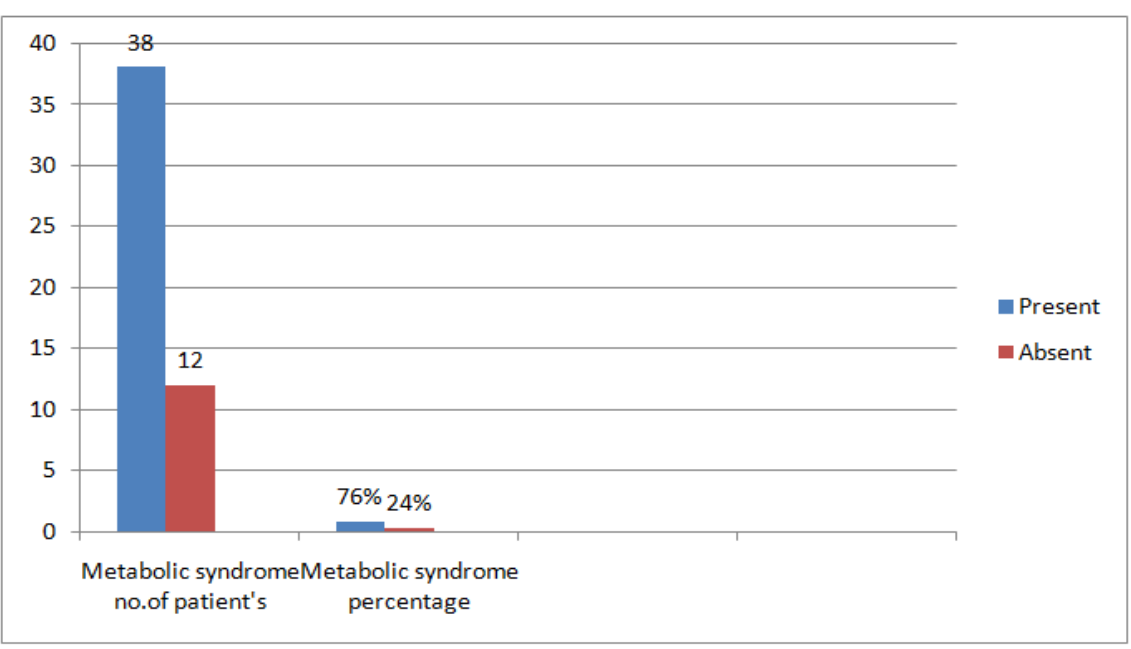




\section{Discussion}

This study confirms the high prevalence of low testosterone levels and of erectile dysfunction in diabetic male patients in a tertiary setting and argue in favour of universal screening of the population group . Multiple predictors of low testosterone levels \& of erectile dysfunction were identified. Erectile dysfunction negatively affected the quality of life. Reports that have clearly established that LST is common and that at least $25 \%$ of men with type 2 diabetes have LST with inappropriately low LH and FSH concentrations are on the increase. Another 4\% have subnormal testosterone concentrations with higher LH and FSH concentrations. Due to a higher prevalence of low testosterone in diabetics, the possibility that LST might contribute to diabetesrelated sexual dysfunction has recently been reevaluated. The present study found that $44 \%$ of patients with T2DM had a TT level of $<3 \mathrm{ng} / \mathrm{ml}, 56 \%$ OF patients with t2dm had normal level of TT levels.And in $46 \%$ had erectile dysfunction and54\% had normal sexual function.

Thus, identification of risk factors and predictors of hypogonadism is essential because of high prevalence and associated co morbidity. Thus the Hbalc, degree of albuminuria and waist circumference were significant risk Observational studies consistently show that obesity is a major determinant of low testosterone, even overriding the effects of age, noting the opposite effects on SHBG, which is arguably the strongest determinant of circulating testosterone. The association of obesity itself with low testosterone was highlighted by the largest case-control study to date, including 400 diabetic men and 1400 nondiabetic controls . Although $51 \%$ of diabetic men had low free testosterone, it was also low in $30 \%$ of the nondiabetic controls. Nevertheless, diabetic men still had significantly lower total and free testosterone than controls.

\section{Refrences}

[1]. International Diabetes Federation. IDF Diabetes Atlas. Epidemiology and Mobidity. International Diabetes Federation.

[2]. Chan JC, Malik V, Jia W, Kadowaki T, Yajnik CS, Yoon KH, et al. Diabetes in Asia: Epidemiology, risk factors, and pathophysiology. JAMA. 2009;30:2129-40.

[3]. Ajlouni K, Khader YS, Batieha A, Ajlouni H, El-Khateeb M. An increase in prevalence of diabetes mellitus in Jordan over 10 years. J Diabetes Complications. 2008;22:317-24.

[4]. George JT, Veldhuis JD, Tena-Sempere M, Millar RP, Anderson RA. Exploring the pathophysiology of hypogonadism in men with type 2 diabetes: Kisspeptin-10 stimulates serum testosterone and LH secretion in men with type 2 diabetes and mild biochemical hypogonadism. Clin Endocrinol (Oxf) 2013;79:100-4.

[5]. Ghazi S, Zohdy W, Elkhiat Y, Shamloul R. Serum testosterone levels in diabetic men with and without erectile dysfunction. Andrologia. 2012;44:373-80.

[6]. Kohler TS, Kim J, Feia K, Bodie J, Johnson N, Makhlouf A, et al. Prevalence of androgen deficiency in men with erectile dysfunction. Urology. 2008;71:693-7.

[7]. Rezvani MR, Saadatjou SA, Sorouri S, Hassanpour Fard M. Comparison of serum free testosterone, luteinizing hormone and follicle stimulating hormone levels in diabetics and non-diabetics men- a case-control study. J Res Health Sci. 2012;12:98-100.

[8]. Tamler R, Deveney T. Hypogonadism, erectile dysfunction, and type 2 diabetes mellitus: What the clinician needs to know. Postgrad Med. 2010;122:165-75.

[9]. Grossmann M, Thomas MC, Panagiotopoulos S, Sharpe K, Macisaac RJ, Clarke S, et al. Low testosterone levels are common and associated with insulin resistance in men with diabetes. J Clin Endocrinol Metab.2008;93:1834-40.

[10]. Soriguer F, Rubio-Martin E, Fernandez D, Valdes S, Garcia-Escobar E, Martin-Nunez GM, et al. Testosterone, SHBG and risk of type 2 diabetes in the second evaluation of the Pizarra cohort study. Eur J Clin Invest. 2012;42:79-85.

[11]. Dandona P, Rosenberg MT. A practical guide to male hypogonadism in the primary care setting. Int J Clin Pract. 2010;64:682-96.

[12]. Zhang XW, Liu ZH, Hu XW, Yuan YQ, Bai WJ, Wang XF, et al. Androgen replacement therapy improves psychological distress and health-related quality of life in late onset hypogonadism patients in Chinese population.Chin Med J (Engl) 2012;125:3806-10.

[13]. Dhindsa S, Prabhakar S, Sethi M, Bandyopadhyay A, Chaudhuri A, Dandona P. Frequent occurrence of hypogonadotropic hypogonadism in type 2 diabetes. J Clin Endocrinol Metab. 2004;89:5462-8.

[14]. Laaksonen DE, Niskanen L, Punnonen K, Nyyssonen K, Tuomainen TP, Valkonen VP, et al. Testosterone and sex hormonebinding globulin predict the metabolic syndrome and diabetes in middle-aged men. Diabetes Care. 2004;27:1036-41.

[15]. Saboor Aftab SA, Kumar S, Barber TM. The role of obesity and type 2 diabetes mellitus in the development of male obesityassociated secondary hypogonadism. Clin Endocrinol (Oxf) 2013;78:330-7.

[16]. 16.Kapoor D, Aldred H, Clark S, Channer KS, Jones TH. Clinical and biochemical assessment of hypogonadism in men with type 2 diabetes: Correlations with bioavailable testosterone and visceral adiposity. Diabetes Care. 2007;30:911-7. 